\title{
CORRELATION BETWEEN PERCEPTION ON CLINICAL LEARNING ENVIRONMENTS AND CAREER CHOICE ON CLERKSHIP STUDENTS IN FACULTY OF MEDICINE UNIVERSITAS SEBELAS MARET
}

\author{
Adinda Kharisma Apriliani*, Eti Poncorini Pamungkasari**, Amandha Boy Timor Randita** \\ *Mahasiswa Program Studi Kedokteran FK UNS, Surakarta - Indonesia \\ **Fakultas Kedokteran, Universitas Sebelas Maret, Surakarta - Indonesia
}

\begin{abstract}
Background: Needs of health workers, especially general practitioners, relatively high in Indonesia. Career choices among medical students are various, such as general practitioner, specialist, medical researcher, etc. Many factors affect medical students' career choices, one of them is learning environments. This study aims to prove the correlation between clerkship students' perceptions of clinical learning environments and their career choices.
\end{abstract}

Methods: This research was an analytical observational research with cross sectional approach. The subjects were clerkship students who underwent clinical rotation. The samples were 178 clerkship students from all departments. They were chosen by probability proportional to size sampling. Every respondent was given career choices questionnaire and PHEEM questionnaire which has analyzed for its validity and reliability with $\alpha \geq 0,6(\alpha=0,826)$ and $r \geq 0,30(r=0,442)$. The result of this study was analyzed by Chi-square test and followed by Contingency Coefficient with 95\% confidence level $(\alpha=0,05)$.

Result: The result showed that students' perception of clinical learning environment "good but still need improvement" category was nearly the same as "plenty of problems" category. The result on the students' career choices, most students choose clinical career. There was significant correlation between perception of clinical learning environment and career choices with $p<0,05(p=0,018), x^{2}$ count $\left(x^{2}=5,625\right)>x^{2}$ table $\left(x^{2}=3,841\right)$.

Conclusion: There was very weak correlation between perception of clinical learning environments and career choice on clerkship students.

Keywords: clinical learning environment, perception of clinical learning environment, career choices, PHEEM

\begin{abstract}
ABSTRAK
Latar belakang: Kebutuhan akan tenaga kesehatan, khususnya dokter umum, relatif masih tinggi di Indonesia. Jenis pilihan karir kedokteran di Indonesia sangat bervariasi, seperti dokter umum, dokter spesialis, peneliti, manajemen kesehatan, dan lain-lain. Banyak faktor memengaruhi pilihan karir mahasiswa, salah satunya lingkungan pembelajaran. Tujuan penulis adalah membuktikan bahwa terdapat hubungan antara persepsi lingkungan pembelajaran terhadap pilihan karir pada mahasiswa profesi dokter.

Metode: Penelitian ini adalah penelitian observasional analitik dengan pendekatan cross sectional. Subjek penelitian adalah mahasiswa profesi dokter yang sedang menjalani rotasi klinik. Sampel yang digunakan sebanyak 178 mahasiswa angkatan 2016 dan 2017 dari seluruh stase dengan pemilihan sampel menggunakan probability proportional to size sampling. Setiap responden diberikan kuesioner berupa kuesioner pilihan karir dan kuesioner PHEEM yang telah diuji validitas dan reliabilitasnya dengan nilai $\alpha \geq 0,6 \quad(\alpha=0,826)$ dan $r \geq 0,30(r=0,442)$.
\end{abstract}

contact: adindakharismaa@gmail.com 
Teknik analisis data menggunakan uji chi-square dilanjutkan dengan uji koefisien kontingensi, dengan tingkat kepercayaan 95\% $(\alpha=0,05)$.

Hasil: Persepsi mahasiswa mengenai lingkungan pembelajaran hasilnya hampir sama antara kategori baik namun masih membutuhkan perbaikan dan banyak masalah. Hasil dari pilihan karir, mayoritas mahasiswa memilih karir klinis. Terdapat hubungan yang signifikan antara persepsi lingkungan pembelajaran dan pilihan karir pada mahasiswa program studi profesi Fakultas Kedokteran Universitas Sebelas Maret dengan nilai $p<0,05(p=0,018)$, nilai $x^{2}$ hitung $\left(x^{2}=5,625\right)>x^{2}$ tabel $\left(x^{2}=3,841\right)$ dan kategori korelasi sangat lemah $(r=0,189)$.

Kesimpulan: Terdapat hubungan yang signifikan antara persepsi lingkungan pembelajaran dan pilihan karir pada mahasiswa profesi dokter dengan kekuatan korelasi sangat lemah.

Kata kunci: lingkungan pembelajaran klinik, persepsi lingkungan belajar, pilihan karir, PHEEM

\section{PENDAHULUAN}

Kebutuhan akan profesi kesehatan, terutama di daerah pedesaan, merupakan masalah mayor di seluruh dunia, khususnya di negara berkembang. ${ }^{1}$ Pada tahun 2016, rasio dokter umum terhadap jumlah penduduk di Indonesia belum mencapai target. ${ }^{2,3}$ Ketersediaan tenaga kerja kesehatan dapat dipengaruhi oleh pilihan karir mahasiswa kedokteran. Pilihan karir mahasiswa kedokteran dapat berdampak pada distribusi tenaga kerja kesehatan. ${ }^{4}$

Pilihan karir merupakan salah satu pilihan penting dalam menentukan masa depan seseorang. ${ }^{4}$ Secara garis besar pilihan karir kedokteran berupa klinis dan non-klinis. ${ }^{5}$ Di Indonesia, menurut UndangUndang No. 20 Tahun 2013 tentang Pendidikan Kedokteran dan menurut Konsil Kedokteran Indonesia ${ }^{5}$ karir klinis kedokteran dibagi menjadi tiga, yaitu dokter umum, dokter spesialis, dan dokter spesialis. Pembagian karir non klinis berdasarkan Medical Council of New Zealand ${ }^{6}$ adalah peneliti kedokteran, pendidikan kedokteran, manajemen kesehatan, dan keahlian lain yang spesifik. Proses pemilihan karir dipengaruhi oleh banyak faktor, beberapa di antaranya performa akademik dan pengalaman belajar klinik yang keduanya berkaitan dengan lingkungan pembelajaran. ${ }^{7,8}$

Lingkungan pembelajaran mahasiswa kedokteran terdiri dari tahap sarjana dan profesi klinik. ${ }^{9}$ Program studi profesi dokter adalah pendidikan profesi atau klinik yang dilakukan setelah selesai melaksanakan program sarjana, yang diarahkan pada hasil lulusan yang mempunyai kemampuan dan kompetensi sebagai dokter umum. Sesuai dengan standar yang dibuat oleh Konsil Kedokteran Indonesia ${ }^{5}$, mahasiswa profesi dokter diharuskan mendapat pengalaman belajar di lapangan. Pengalaman belajar didapatkan dari kurikulum pendidikan dokter yang dilaksanakan pada konteks sistem pelayanan kesehatan.

Pada tahun 2011, Okayama dan Kajii ${ }^{10}$ pernah meneliti hubungan community-based education dan pilihan karir pada mahasiswa kedokteran di Jepang. Hasil dari penelitian tersebut adalah communitybased education memengaruhi pilihan karir mahasiswa untuk bekerja di layanan kesehatan komunitas. Selain itu, motivasi mahasiswa dalam memilih karir tersebut juga meningkat karena adanya kegiatan yang mendukung, yaitu edukasi kesehatan secara langsung. Di Indonesia, pada tahun 2015 Maulidira et al. ${ }^{11}$ pernah dilakukan penelitian mengenai hubungan role model terhadap pilihan karir pada mahasiswa kedokteran. Dari penelitian tersebut, dapat diambil kesimpulan bahwa role model dapat memengaruhi pilihan karir mahasiswa.

Salah satu faktor yang mempengaruhi persepsi mahasiswa dalam mennetukan karir atau masa depan mereka setelah lulus profesi dokter adalah lingkungan belajar tahap klinik. Lingkungan belajar yang mendukung suatu minat tertentu, akan memberikan insight tersendiri di mahasiswa, yang kemudian bisa menjadi hal yang mempengaruhi pilihan minat pada tahap pendidikan atau pekerjaan 
selanjutnya. Namun, sebaliknya, lingkungan belajar yang tidak mendukung suatu minat dari mahasiswa, maka akan menimbulkan persepsi yang berbeda pula $^{10,11}$. Di Indonesia penelitian yang mengkaji mengenai hubungan lingkungan pembelajaran dengan pilihan karir mahasiswa pada program studi profesi dokter masih jarang dilakukan. Oleh karena itu penelitian ini bertujuan untuk mengetahui persepsi mahasiswa profesi dokter terkait lingkungan pembelajaran klinik dengan dihubungkan pada pilihan karir.

\section{METODE}

Penelitian ini merupakan penelitian analitik observasional dengan pendekatan cross sectional yaitu variabel bebas dan variabel tergantung diukur satu kali dalam kesempatan yang sama. Penelitian dilaksanakan di Rumah Sakit Dr. Moewardi yang merupakan rumah sakit pendidikan utama Fakultas Kedokteran Universitas Sebelas Maret pada bulan Januari sampai Februari 2018. Subjek penelitian ini adalah dokter muda Fakultas Kedokteran Universitas Sebelas Maret dengan populasi 330 orang yang terbagi dalam 18 stase dengan jumlah mahasiswa yang berbeda-beda pada tiap stase. Berdasarkan hasil perhitungan sampel menggunakan program OpenEpi dengan tingkat kesalahan 5\%, minimal sampel yang diambil adalah 178 orang. Teknik sampling yang digunakan adalah probability proportional to size sampling yaitu sampel dipilih berdasarkan perbandingan proporsional dari jumlah mahasiswa dalam stase per jumlah mahasiswa keseluruhan dan dikalikan dengan minimal sampel yang diambil yang kemudian disesuaikan dengan kriteria inklusi dan eksklusi yang sudah ditetapkan, sehingga didapatkan sampel yang mewakili setiap stase.

Variabel bebas dari penelitian ini adalah persepsi mahasiswa mengenai lingkungan pembelajaran klnik, didefinisikan sebagai skor dari kuesioner yang digunakan. Persepsi mahasiswa mengenai lingkungan pembelajaran klnik diukur dengan menggunakan kuesioner Postgraduate Hospital Educational Environment Measure (PHEEM). Skala pengukuran dari variabel ini adalah kategorikal ordinal. Variabel terikat dari penelitian ini adalah pilihan karir, didefinisikan sebagai karir kedokteran yang dipilih oleh mahasiswa sebagai karir masa depannya. Pengukuran pilihan karir dilakukan dengan menggunakan kuesioner pilihan karir. Skala pengukuran dari variabel ini adalah kategorikal nominal.

\section{HASIL DAN PEMBAHASAN}

Berdasarkan kuesioner yang dibagikan, diperoleh 178 subjek memenuhi kriteria dari 18 stase. Berdasarkan pada Tabel 1, jumlah responden berjenis kelamin laki-laki lebih sedikit daripada responden perempuan dan mayoritas berusia 22 tahun. Alasan masuk Fakultas Kedokteran didominasi oleh alasan karena dirinya sendiri. Pada tahun masuk profesi, sebagian besar responden yang mengisi kuesioner masuk pada periode tahun 2017. Untuk jumlah stase yang telah diikuti, sebagian besar responden baru mengikuti 8 stase. IPK S1 dalam rentang 3,00-3,50 (lulus dengan sangat memuaskan) ada $130(73,0 \%)$ mahasiswa, sedangkan rentang IPK 3,51-4,00 (lulus dengan predikat cumlaude) ada 13 (7,3\%) mahasiswa. 
Tabel 1. Deskripsi Responden Penelitian

\begin{tabular}{|c|c|c|}
\hline Karakteristik & $\begin{array}{l}\text { Frekuensi } \\
\text { (n) }\end{array}$ & $\begin{array}{c}\text { Persen } \\
(\%)\end{array}$ \\
\hline $\begin{array}{l}\text { Jenis Kelamin } \\
\text { Laki- laki } \\
\text { Perempuan }\end{array}$ & $\begin{array}{r}59 \\
119\end{array}$ & $\begin{array}{l}33,1 \% \\
66,9 \%\end{array}$ \\
\hline $\begin{array}{l}\text { Usia (tahun) } \\
20 \\
21 \\
22 \\
23 \\
24 \\
25\end{array}$ & $\begin{array}{r}3 \\
31 \\
85 \\
45 \\
11 \\
3\end{array}$ & $\begin{array}{r}1,7 \% \\
17,4 \% \\
47,8 \% \\
25,3 \% \\
6,2 \% \\
1,7 \%\end{array}$ \\
\hline $\begin{array}{l}\text { Alasan masuk FK } \\
\text { Diri Sendiri } \\
\text { Orang Tua } \\
\text { Lainnya }\end{array}$ & $\begin{array}{r}136 \\
36 \\
6\end{array}$ & $\begin{array}{r}76,4 \% \\
20,2 \% \\
3,4 \%\end{array}$ \\
\hline $\begin{array}{l}\text { Tahun masuk profesi } \\
2016 \\
2017\end{array}$ & $\begin{array}{r}46 \\
132\end{array}$ & $\begin{array}{l}25,8 \% \\
74,2 \%\end{array}$ \\
\hline $\begin{array}{l}\text { Jumlah stase yang telah diiku } \\
1 \\
2 \\
3 \\
4 \\
5 \\
6 \\
7 \\
8 \\
9 \\
10 \\
11 \\
12 \\
13 \\
14 \\
15 \\
16 \\
17 \\
\text { Tidak mengisi }\end{array}$ & $\begin{array}{r}1 \\
13 \\
13 \\
3 \\
2 \\
15 \\
5 \\
56 \\
9 \\
8 \\
4 \\
2 \\
9 \\
12 \\
4 \\
19 \\
1 \\
2\end{array}$ & $\begin{array}{r}0,6 \% \\
7,3 \% \\
7,3 \% \\
1,7 \% \\
1,1 \% \\
8,4 \% \\
2,8 \% \\
31,5 \% \\
5,1 \% \\
4,5 \% \\
2,2 \% \\
1,1 \% \\
5,1 \% \\
6,7 \% \\
2,2 \% \\
10,7 \% \\
0,6 \% \\
1,1 \%\end{array}$ \\
\hline $\begin{array}{l}\text { IPK S1 } \\
\begin{array}{r}3,00-3,50 \\
3,51-4,00\end{array}\end{array}$ & $\begin{array}{r}130 \\
13\end{array}$ & $\begin{array}{r}73,0 \% \\
7,3 \%\end{array}$ \\
\hline Tidak teridentifikasi & 35 & $19,7 \%$ \\
\hline
\end{tabular}

Berdasar pada Tabel 2, hasil pengukuran persepsi mengenai lingkungan pembelajaran klinik dengan kuesioner PHEEM menunjukkan hasil yang hampir sama antara kategori persepsi baik, namun masih membutuhkan perbaikan dengan kategori banyak masalah. Hasil pengukuran pilihan karir menunjukkan hasil paling banyak adalah pada kategori pilihan karir klinis. 
Tabel 2. Distribusi Frekuensi Lingkungan Pembelajaran dan Pendekatan Belajar

\begin{tabular}{lccccc} 
& \multicolumn{5}{c}{ Lingkungan Pembelajaran } \\
\cline { 2 - 5 } \multicolumn{1}{c}{ Pilihan Karir } & $\begin{array}{c}\text { Sangat } \\
\text { Buruk }\end{array}$ & $\begin{array}{c}\text { Banyak } \\
\text { Masalah }\end{array}$ & $\begin{array}{c}\text { Baik, Butuh } \\
\text { Perbaikan }\end{array}$ & $\begin{array}{c}\text { Sangat } \\
\text { Baik }\end{array}$ & Total \\
Dokter Umum & 1 & 2 & 1 & 0 & $4(2,2 \%)$ \\
Dokter Spesialis/Dokter Subspesialis & 0 & 64 & 76 & 3 & $143(80,3 \%)$ \\
Akademisi/Peneliti & 0 & 10 & 2 & 0 & $12(6,7 \%)$ \\
Manajemen Kesehatan/Pemangku Kebijakan & 0 & 7 & 7 & 0 & $14(7,9 \%)$ \\
Lainnya & 0 & 5 & 0 & 0 & $5(2,9 \%)$ \\
\hline \multicolumn{1}{c}{ Total } & $1(0,6 \%)$ & $88(48,9 \%)$ & $86(47,8 \%)$ & $3(1,7 \%)$ & $178(100 \%)$ \\
\hline
\end{tabular}

Berdasarkan Tabel 3, didapatkan adanya nilai 0 pada nilai expected yang berarti data tersebut tidak memenuhi syarat uji komparatif chi-square, sehingga menurut $\mathrm{Wyllys}^{13}$ perlu dilakukan penggabungan data berupa collapsing pada kedua variabel supaya nilai expected tidak sama dengan 0 , sehingga variabel persepsi lingkungan pembelajaran klinik yang sebelumnya memiliki empat kategori yaitu "sangat buruk", "banyak masalah", "lebih baik, namun butuh perbaikan", dan "sangat baik"; digabungkan menjadi dua kategori yaitu "banyak masalah" dan "lebih baik, namun butuh perbaikan". Hal tersebut dilakukan karena data responden dengan persepsi lingkungan pembelajaran klinik "sangat buruk" dan "sangat baik" terlalu sedikit. Selain itu, pada variabel pilihan karir, data yang digabungkan yaitu kategori "dokter umum" dan kategori "dokter spesialis/ sub spesialis" dikategorikan sebagai pilihan karir "klinis", sedangkan kategori "akademisi/peneliti", "manajemen kesehatan/pemangku kebijakan", dan "lainnya" dikategorikan sebagai pilihan karir "non klinis".

Tabel 3. Hasil Analisis Data Menggunakan Uji Chi-Square

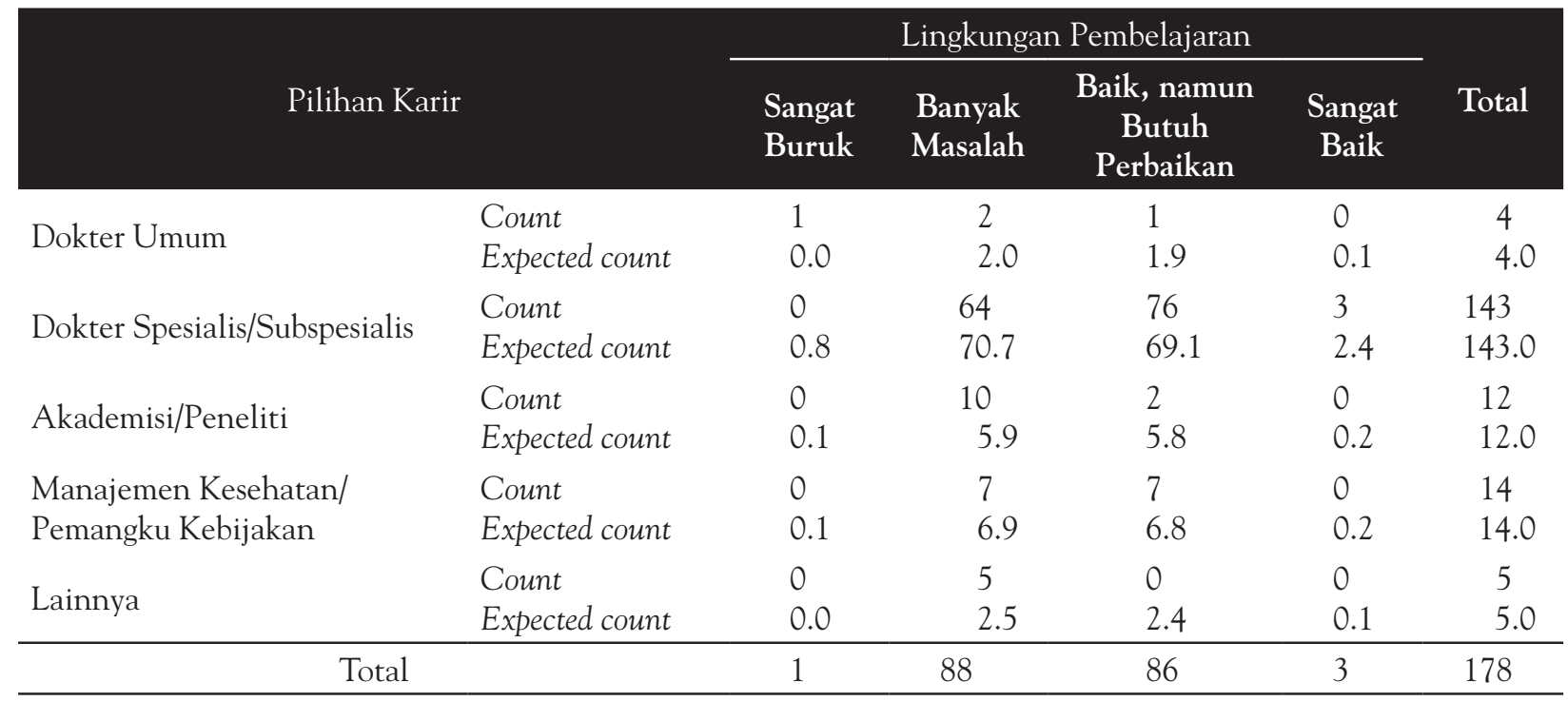

Kemudian data tersebut diuji ulang menggunakan uji komparatif chi-square dangan hasil yang dapat dilihat pada Tabel 4. Pada tabel 4 diperoleh hasil dengan nilai $p=0,018$ yang berarti $p<0,05$ menunjukkan bahwa terdapat hubungan yang signifikan antara lingkungan pembelajaran dengan pilihan karir. Namun, kekuatan hubungan antara dua variabel tersebut tergolong sangat lemah yang dibuktikan dengan nilai koefisien kontingensi $(r)$ sebesar 0,189. 
Tabel 4. Hasil Analisa Uji Chi-Square Setelah Penggabungan Data

\begin{tabular}{|c|c|c|c|c|c|c|c|}
\hline & & Lingkunga & embelajaran & & & & \\
\hline & Ian Karir & $\begin{array}{l}\text { Banyak } \\
\text { Masalah }\end{array}$ & $\begin{array}{c}\text { Baik, namun } \\
\text { Butuh } \\
\text { Perbaikan }\end{array}$ & Total & $\mathrm{X}^{2}$ & p & $\mathbf{r}$ \\
\hline Klinis & $\begin{array}{l}\text { Count } \\
\text { Expected count }\end{array}$ & $\begin{array}{c}67(45,6 \%) \\
73,5\end{array}$ & $\begin{array}{c}80(54,4 \%) \\
73,5\end{array}$ & $\begin{array}{c}147(100 \%) \\
147,0\end{array}$ & & & \\
\hline Non Klinis & $\begin{array}{l}\text { Count } \\
\text { Expected count }\end{array}$ & $\begin{array}{c}22(71,0 \%) \\
15,5\end{array}$ & $\begin{array}{c}9(29,0 \%) \\
15,5 \\
\end{array}$ & $\begin{array}{c}31(100 \%) \\
31,0\end{array}$ & 5,625 & 0,018 & 0,189 \\
\hline & Total & 89 & 89 & 178 & & & \\
\hline
\end{tabular}

Secara umum, dari 178 responden yang mengisi kuesioner PHEEM, ada 88 (48,9\%) mahasiswa yang memiliki persepsi lingkungan banyak masalah, $86 \quad(47,8 \%)$ mahasiswa berpersepsi bahwa lingkungan pembelajaran kliniknya "baik, namun masih membutuhkan perbaikan”, 3 (1,7\%) mahasiswa memiliki persepsi terhadap lingkungan pembelajaran kliniknya "sangat baik", dan ada $1(0,6 \%)$ mahasiswa yang berpersepsi bahwa lingkungan pembelajarannya "sangat buruk". Hasil tersebut berbeda dengan penelitian Binsaleh et al. ${ }^{14}$ pada 72 residen urologi di Universitas King Saud, Saudi Arabia. Pada penelitian tersebut diperoleh hasil penilaian PHEEM menunjukkan 38 responden $(52,7 \%)$ memiliki persepsi lingkungan pembelajaran "baik namun masih membutuhkan perbaikan" dan 34 responden (47,2\%) berpersepsi "banyak masalah". Faktor-faktor yang memengaruhi perbedaan hasil penelitian tersebut salah satu di antaranya adalah lingkungan pendidikan klinik, sehingga pendidikan klinik perlu mendapatkan perhatian penuh di semua bagiannya agar persepsi terhadap lingkungan klinik lebih banyak ke arah positif. Selain itu, kurangnya protokol klinis yang jelas, beban kerja, jam kerja, kualitas pengawasan pengajaran, kurangnya fasilitas, dan kurangnya lingkungan rumah sakit yang mendukung mengakibatkan masih terdapat juga persepsi yang mengarah pada kategori banyak masalah. ${ }^{14}$

Hasil tersebut juga berbeda dengan penelitian yang dilakukan Al-Marshad dan Alotaibi ${ }^{15}$ di Dammam University pada 137 residen yakni secara keseluruhan persepsi mengenai lingkungan pembelajaran klinik adalah baik, akan tetapi masih ada aspek yang penting untuk diperbaiki. Perbedaan pada hasil penelitian ini dapat terjadi karena beberapa faktor di antaranya adalah perbedaan sistem pendidikan yang digunakan pada rumah sakit pendidikan, fasilitas yang disediakan rumah sakit pendidikan, situasi responden ketika pengisian kuesioner, dan perbedaan usia responden.

Hasil penelitian ini menunjukkan responden sebagian besar memilih karir sebagai dokter spesialis atau dokter subspesialis yaitu sebesar 143 (80,34\%) mahasiswa. Hal ini sesuai dengan penelitian Bhat et al. ${ }^{16}$, yang menyatakan bahwa mayoritas mahasiswa kedokteran memilih karir sebagai dokter spesialis dibandingkan dengan karir sebagai dokter umum atau layanan primer, bidang non klinis, maupun non medis. Faktor-faktor yang dapat memengaruhi hal tersebut di antaranya karakteristik karir, seperti penghasilan, prospek kerja, lokasi kerja, dan jam kerja, serta ketertarikan personal. Penelitian yang dilakukan oleh Kim et al. ${ }^{17}$ mengatakan tidak terdapat perbedaan signifikan antara mahasiswa yang memilih karir klinis dan non klinis, namun terdapat perbedaan persepsi dalam mempelajari bidang kedokteran.

Melalui penelitian ini diketahui bahwa persepsi lingkungan pembelajaran klinik memiliki hubungan yang signifikan $(p=0,018)$ terhadap pilihan karir, dengan kekuatan korelasi sangat lemah $(r=0,189)$. Hasil ini sesuai dengan penelitian Anuja ${ }^{18}$ dengan hasil antara lingkungan dan pilihan karir berhubungan secara signifikan $(\mathrm{p}=0,004)$ dengan kekuatan korelasi lemah $(r=0,422)$. Oleh karena itu, dapat disimpulkan bahwa lingkungan pembelajaran kurang memengaruhi pilihan karir seseorang. 
Keterbatasan penelitian ini adalah masih menggunakan pendekatan cross sectional sehingga hanya bisa mengetahui persepsi mahasiswa mengenai lingkungan pembelajaran klinik dan juga pilihan karir hanya pada satu waktu saja. Pada persepsi mengenai lingkungan pembelajaran klinik, ada faktor-faktor lain yang mempengaruhi pilihan karir yang belum diteliti.

\section{KESIMPULAN}

Berdasar hasil studi ini dapat disimpulkan bahwa terdapat hubungan antara persepsi lingkungan pembelajaran klinik dengan pilihan karir mahasiswa profesi dokter $(\mathrm{p}=0,018)$ dengan korelasi yang sangat lemah $(\mathrm{r}=0,189)$.

\section{DAFTAR PUSTAKA}

1. Amalba A, van Mook W, Mogre V, Scherpbier A. The effect of Community Based Education and Service (COBES) on medical graduates' choice of specialty and willingness to work in rural communities in Ghana. BMC Medical Education. 2016;16(1):1-7.

2. Kementerian Koordinator Bidang Kesejahteraan Rakyat Republik Indonesia. Keputusan Menteri Koordinator Bidang Kesejahteraan Rakyat Nomor 54 Tahun 2013 tentang Rencana Pengembangan Tenaga Kesehatan Tahun 2011-2025 [document on the internet]. Kementerian Republik Indonesia; 2013 [cited 2017 September 30]. Available from: http://www.observatorisdmkindonesia.org/wpcontent/uploads/2014/08/FINAL-KEPMENKORPTK-1.pdf

3. Badan Pengembangan dan Pemberdayaan Sumber Daya Manusia Kesehatan Kementerian Kesehatan Republik Indonesia. Data Tenaga Medis yang didayagunakan di Fasilitas Pelayanan Kesehatan (Fasyankes) [document on the internet]. Kementerian Kesehatan Republik Indonesia; 2016 [cited 2017 September 30]. Available at http:// bppsdmk.kemkes.go.id/info_sdmk/info/

4. Syakurah RA, Sari DA, Riansyah D, Yolanda P. Determinan Pilihan Karier Mahasiswa Fakultas Kedokteran Sebagai Spesialis di Indonesia. Jurnal Pendidikan Kedokteran Indonesia. 2014;3(2):132136.

5. Konsil Kedokteran Indonesia. Standar Kompetensi Dokter Indonesia [document on the internet].
Konsil Kedokteran Indonesia; 2012 [cited 2017 Oktober 5]. Available at http://pd.fk.ub.ac.id/wpcontent/uploads/2013/08/KKI-SKDI-2012.pdf

6. Medical Council of New Zealand. Definition medicine and clinical practice [document on the internet]. Medical Council of New Zealand; 2013 [cited 2017 Desember 3]. Available at https://www. mcnz.org.nz/assets/Policies/Definition-of-clinicaland-non-clinical-practice.pdf

7. Coffeng LE, Visscher AJE, Cate OTHJ. The influence of early clinical experiences on career preference of male and female medical students. Medical Teacher. 2009; 31(7):323-326.

8. Takeda Y, Morio K, Snell L, Otaki J, Takahashi M, Kai I. Characteristic profiles among students and junior doctors with specific career preferences. BMC Medical Education. 2013; 13(1): 1-11.

9. Konsil Kedokteran Indonesia. Standar Pendidikan Profesi Dokter Indonesia. Konsil Kedokteran Indonesia; 2012 [cited 2017 Oktober 5]. Available at http://www.kki.go.id/assets/data/arsip/Final_ SPPDI,_21_Maret_2013.pdf

10. Okayama, M. and Kajii, E. Does community-based education increase students' motivation to practice community health care? - a cross sectional study. BMC Medical Education. 2012;11(1): 2-7.

11. Maulidira F, Syakurah RA, Fadilah M, Aulia.H. Pengaruh role model terhadap pilihan karir pada mahasiswa fakultas kedokteran. Jurnal Pendidikan Kedokteran Indonesia. 2015; 4(2):75-82.

12. Prasetyawati AE. Hubungan antara lingkungan belajar klinis dan kemampuan metakognitif dengan kompetensi koasisten dalam menjalani kepaniteraan klinik di RSUD dr. Moewardi Surakarta [dissertation]. Surakarta (Indonesia): Universitas Sebelas Maret; 2010.

13. Wyllys RE. The Chi-Square Tests and Their Uses. Austin: The University of Texas at Austin School of Information; 2003.

14. Binsaleh S, Babaeer A, Alkhayal A, dan Madbouly K. Evaluation of the learning environment of urology residency training using the postgraduate hospital educational environment measure inventory. Adv Med Educ Pract. 2015; 6: 271-277.

15. Al-Marshad S, Alotaibi G. Evaluation of Clinical Educational Environment at King Fahad Hospital of Dammam University Using the Postgraduate Hospital Education Environment Measure (PHEEM) Inventory. Education in Medicine Journal. 2011; 3:6-14. 
16. Bhat, Smitha, Landric D'souza dan Jeffrey Fernandez. Factors Influencing the Career Choices of Medical Graduates. 2012; 49: 482-489.

17. Kim KJ, Park JH, Lee YH, Choi K. What is different about medical students interested in non-clinical careers?. BMJ Medical Education. 2013; 13(81).
18. Anuja R. The relationship between Career Choice and environment, opportunity and personality. International Journal of Scientific \& Engineering Research. 2017;8(3) 